\title{
EDUCAÇÃO INCLUSIVA: O TRABALHO PEDAGÓGICO DO PROFESSOR PARA COM O ALUNO AUTISTA NO ENSINO FUNDAMENTAL I
}

\author{
EDUCACIÓN INCLUSIVA: EL TRABAJO PEDAGÓGICO DEL PROFESOR PARA EL \\ ESTUDIANTE AUTISTA EN LA ESCUELA PRIMARIA I
}

\section{INCLUSIVE EDUCATION: THE PEDAGOGICAL WORK OF THE TEACHER FOR THE AUTISTIC STUDENT IN ELEMENTARY SCHOOL I}

\author{
Ariane Mieko Himeno ONOHARA ${ }^{1}$ \\ José Anderson SANTOS CRUZ ${ }^{2}$ \\ Maria Luiza MARIANO ${ }^{3}$
}

RESUMO: O presente artigo foi investigar o trabalho pedagógico/docente das professoras para com os alunos público-alvo da educação especial, particularmente no que se refere a alunos com transtorno do espectro autista (TEA). Para tal, foi realizada uma pesquisa de campo com uma abordagem qualitativa de pesquisa e teve como procedimento metodológico, o Estudo de Caso, utilizando a coleta de dados, a partir de um questionário semiestruturado com 7 perguntas abertas. Participaram do estudo três professoras de uma escola municipal de ensino fundamental I de Bauru, na qual cada uma delas, respectivamente, obteve experiencias diversas para com o aluno, atualmente inserido no ano de 2018 do $3^{\circ}$ ano, destacando as interações sociais vivenciadas e visando as dificuldades enfrentadas pelas professoras no trabalho docente, apesar de possuírem a formação continuada, a psicopedagogia, no que teve o objetivo aproximar a pesquisa com a realidade. Como resultado, verificou-se, que existe muitas barreiras a serem ultrapassadas até podermos denominar de trabalho efetivo, dentro da educação inclusiva sobre o perfil desse público. Também verificada, através dos questionários, que o aluno, utiliza-se de práticas colaborativas ofertadas pela escola que incluem não apenas a professora regular, mas também da professora especialista, que atua no Atendimento Educacional Especializado (AEE), na sala de recursos e o auxílio de uma cuidadora para acompanha-lo, na aplicabilidade das atividades adaptadas, de acordo com a professora. Concluiu que apesar das professoras possuírem formação continuada sobre o assunto abordado, ainda enfrentam dificuldades no trabalho pedagógico.

PALAVRAS-CHAVE: Educação fundamental I. Educação inclusiva. Atendimento educacional especializado. Transtorno do espectro autista. Trabalho pedagógico.

RESUMEN: El presente artículo fue investigar el trabajo pedagógico/docente de los docentes a los estudiantes de educación especial dirigidos al público, especialmente en lo que

\footnotetext{
${ }^{1}$ Faculdade Anhanguera de Bauru, Bauru - SP - Brasil. Pedagoga. Agente Educacional- cuidador de jovens, crianças e adultos no município de Bauru. ORCID: <https://orcid.org/0000-0002-5602-6504>. E-mail: enairaono@yahoo.com.br

${ }^{2}$ Faculdade Anhanguera de Bauru, Bauru - SP - Brasil. Professor A do Departamento de Pedagogia Graduação. Doutorando em Educação Escolar pela Faculdade de Ciências e Letras (UNESP). ORCID: <https://orcid.org/0000-0001-5223-8078>.E-mail: joseandersonsantoscruz@ gmail.com

${ }^{3}$ Faculdade Anhanguera de Bauru, Bauru - SP - Brasil. Coordenadora e Professora do Departamento de Pedagogia e Psicologia - Graduação. ORCID: <https://orcid.org/0000-0002-9148-2732>. E-mail: maria.lalegria@anhanguera.com
} 
respecta a los estudiantes con trastorno del espectro autista (ASD). Con este fin, se realizó una investigación de campo con un enfoque cualitativo de investigación y se tuvo como procedimiento metodológico, el estudio de caso, utilizando recopilación de datos, a partir de un cuestionario semiestructurado con 7 preguntas abiertas. Participó en el estudio tres profesores de una escuela primaria municipal I de Bauru, en la cual cada uno de ellos, respectivamente, obtuvo diversas experiencias para el alumno, actualmente insertada en el año 2018 del 3 er año, destacando las interacciones sociales Experimentado y orientado a las dificultades que enfrentan los docentes en el trabajo docente, aunque poseen la formación continua, la psicopedagógica, en la que se pretende aproximar la investigación con la realidad. Como resultado, se verificó que hay muchas barreras que hay que superar hasta que podamos llamarla trabajo eficaz, dentro de la educación inclusiva sobre el perfil de este público. También se verificó, a través de los cuestionarios, que el estudiante utiliza prácticas de colaboración ofrecidas por la escuela que incluyen no sólo al maestro regular, sino también al profesor especialista, que trabaja en el servicio educativo especializado (AEE), En la sala de recursos y la asistencia de un cuidador para acompañarlo, en la aplicabilidad de las actividades adaptadas, según el profesor. Concluyó que aunque los docentes han continuado la formación sobre el tema abordado, todavía enfrentan dificultades en el trabajo pedagógico.

PALABRAS CLAVE: Educación elemental I; Educación inclusiva; Servicio educativo especializado; Trastorno del espectro Autista; Trabajo pedagógico.

ABSTRACT: The present article was to investigate the pedagogical/teaching work of teachers to the public-target students of special education, particularly with regard to students with autism spectrum disorder (ASD). To this end, a field research was carried out with a qualitative research approach and had as a methodological procedure, the case study, using data collection, from a semi-structured questionnaire with 7 open questions. Participated in the study three teachers of a municipal elementary school I of Bauru, in which each of them, respectively, obtained diverse experiences for the student, currently inserted in the year 2018 of the 3rd year, highlighting the social interactions Experienced and aimed at the difficulties faced by teachers in teaching work, although they possess the continuing education, the Psychopedagogy, in which it was aimed to approximate the research with reality. As a result, it was verified that there are many barriers to be overcome until we can call it effective work, within inclusive education on the profile of this public. Also verified, through the questionnaires, that the student uses collaborative practices offered by the school that include not only the regular teacher, but also the specialist teacher, who works in the Specialized Educational Service (AEE), In the resource room and the assistance of a caregiver to accompany it, in the applicability of the adapted activities, according to the teacher. He concluded that although the teachers have continued training on the subject addressed, they still face difficulties in the pedagogical work.

KEY WORDS: Elementary education I. Inclusive education. Specialized educational service. Autistic spectrum disorder. Pedagogical work.

\section{Introdução}

De acordo com as Diretrizes Curriculares Nacionais da Educação Básica (2013): 
o Ensino Fundamental tem constituído foco central da luta pelo direito à educação. Em consequência, no Brasil, nos últimos anos, sua organização e seu funcionamento têm sido objeto de mudanças que se refletem nas expectativas de melhoria de sua qualidade e de ampliação de sua abrangência, consubstanciadas em novas leis, normas, sistemas de financiamento, sistemas de avaliação e monitoramento, programas de formação e aperfeiçoamento de professores e, o mais importante, em preocupações cada vez mais acentuadas quanto à necessidade de um currículo e de novos projetos político-pedagógicos que sejam capazes de dar conta dos grandes desafios educacionais da contemporaneidade (BRASIL, 2013, p. 103).

Entende-se, com a Lei $\mathrm{n}^{\mathrm{o}} 11.274 / 2006$, o Ensino Fundamental passou para 9 anos, abrangendo crianças, a partir de 6 anos até 14 anos e para aqueles que não concluíram na idade certa, ou por alguma razão não conseguiram frequentar a escola. Nessa fase os mesmos são despertados pela curiosidade, surgidas das interações culturais e sociais (BRASIL, 2013). Nesse sentido, a cada ano que a criança permeia, percebe-se mudanças no comportamento, devidas ao processo de ensino-aprendizagem, com base nisso, ressalta-se, pensar sobre a inserção de todos os alunos.

Nessa perspectiva, a Organização das Nações Unidas para a Educação, a Ciência e a Cultura (UNESCO, 2008 apud RODRIGUES; RODRIGUES, 2011) elenca:

Um conceito alargado de Educação Inclusiva pode ser concebido como um princípio e uma orientação geral para fortalecer a educação, com vista a um desenvolvimento sustentável, aprendizagem ao longo da vida para todos e acesso igual de todos os níveis da sociedade às oportunidades de aprendizagem.

Cabe destacar que a educação inclusiva, abrange todos, independente de gêneros, religião e ou outros motivos, que enfrentam discriminações na sociedade, fato que deve estar destacada no direito de o educando estar inserido no ensino regular, assim superando barreiras durante a aprendizagem.

Nesse sentido Fávero (2009), destaca o direito de todos os educandos terem acesso a uma educação de qualidade, de modo a suprir as suas necessidades de aprendizado básico, visando promover ou facilitar o seu dia a dia.

Considera-se que o processo de desenvolvimento não ocorre de forma plena em alguns alunos, cabendo uma investigação mais profunda com apoio especializado, dentro e fora do ambiente escolar, se o aluno fora constatado alguma deficiência que o impeça a compreensão do conteúdo. Cita-se: 
Em 1994, se constitui, na Espanha, a Declaração de Salamanca que tem por objetivo discutir a questão das pessoas com necessidades especiais. Com o intuito de cumprir esses acordos, o Brasil tem criado instrumentos norteadores e documentos legais com o objetivo de possibilitar a criação de sistemas educacionais que sejam inclusivos. (FARIA; SANTOS; SILVA, 2009, p. 41).

Neste aspecto a criação de sistemas inclusivos educacionais tem sido muito exigida devido ao aumento da inserção dos educandos em escolas de ensino regular, considerando diferentes características e necessidades, destacando o despreparo da comunidade educacional envolvida no processo. Dado o Capítulo V do Título da Educação Especial, contida na Lei de Diretrizes de Bases, art. 59, Inciso I “[...] currículos, métodos, técnicas, recursos educativos e organização específicos para atender as suas necessidades; “ (LDBE, Lei 9394/96, Art. 59, Inciso I).

De acordo com a Política Nacional de Educação Especial na Perspectiva da Educação Inclusiva define-se que:

Em todas as etapas e modalidades da educação básica, o atendimento educacional especializado é organizado para apoiar o desenvolvimento dos alunos, constituindo oferta obrigatória dos sistemas de ensino. Deve ser realizado no turno inverso ao da classe comum, na própria escola ou centro especializado que realize esse serviço educacional [...] (BRASIL, 2007, p. 16).

Nesta perspectiva, a Educação Inclusiva pode contribuir na socialização desses alunos para com os outros e os beneficiando, ao adquirir o respeito pelas diferenças. Para tanto é importante destacar que:
A inclusão é uma inovação que implica um esforço de modernização e de reestruturação das condições atuais da maioria de nossas escolas [...] (especialmente as de nível básico), ao assumirem que as dificuldades de alguns alunos não são apenas deles, mas resultam, em grande parte, do modo como o ensino é ministrado e de como a aprendizagem é concebida e avaliada. (MANTOAN, 2003, p. 32).

Nesse contexto considera importante favorecer uma aprendizagem no qual resulte, o conhecimento, tendo objetivos e processos diferentes mesmo diante das dificuldades e desafios do processo da inclusão.

Nesse segmento, surge o Atendimento Educacional Especializado (AEE), serviço oferecido nas escolas comuns, chamados de Sala de Recursos, que possui a função de suplementar e ou completar a formação do aluno, sempre trabalhando de forma a garantir a autonomia dentro e fora do ambiente escolar. 
A Resolução do Conselho Nacional de Educação/Câmara de Educação Básica CNE/CEB, No 4/2009, artigo $4^{\circ}$, considera público-alvo do AEE:

I - Alunos com deficiência: aqueles que têm impedimentos de longo prazo de natureza física, intelectual, mental ou sensorial.

II - Alunos com transtornos globais do desenvolvimento: aqueles que apresentam um quadro de alterações no desenvolvimento neuropsicomotor, comprometimento nas relações sociais, na comunicação ou estereotipias motoras. Incluem-se nessa definição alunos com autismo clássico, síndrome de Asperger, síndrome de Rett, transtorno desintegrativo da infância (psicoses) e transtornos invasivos sem outra especificação.

III - Alunos com altas habilidades/superdotação: aqueles que apresentam um potencial elevado e grande envolvimento com as áreas do conhecimento humano, isoladas ou combinadas: intelectual, liderança, psicomotora, artes e criatividade (BRASIL, 2009).

Diante da Resolução do CNE/CEB, os alunos excluídos do processo educacional, tornam o público-alvo da Educação Especial, ou seja, alunos que possui alguma deficiência, inseridos no AEE da escola em que estuda, resultando nas melhores condições de aprendizagem.

Assim a professora do AEE, possui obrigações:

Art. 13. São atribuições do professor do Atendimento Educacional Especializado: I - identificar, elaborar, produzir e organizar serviços, recursos pedagógicos, de acessibilidade e estratégias considerando as necessidades específicas dos alunos público-alvo da Educação Especial; II elaborar e executar plano de Atendimento Educacional Especializado, avaliando a funcionalidade e a aplicabilidade dos recursos pedagógicos e de acessibilidade; III - organizar o tipo e o número de atendimentos aos alunos na sala de recursos multifuncionais; IV - acompanhar a funcionalidade e a aplicabilidade dos recursos pedagógicos e de acessibilidade na sala de aula comum do ensino regular, bem como em outros ambientes da escola; V estabelecer parcerias com as áreas intersetoriais na elaboração de estratégias e na disponibilização de recursos de acessibilidade; VI - orientar professores e famílias sobre os recursos pedagógicos e de acessibilidade utilizados pelo aluno; VII - ensinar e usar a tecnologia assistiva de forma a ampliar habilidades funcionais dos alunos, promovendo autonomia e participação; VIII - estabelecer articulação com os professores da sala de aula comum, visando à disponibilização dos serviços, dos recursos pedagógicos e de acessibilidade e das estratégias que promovem a participação dos alunos nas atividades escolares (BRASIL, 2009).

Nesse sentido, considera imprescindível que a inclusão no ambiente escolar, exige comprometimento dos professores de sala de aula e todos os envolvidos, assim possibilitando resultados positivos no ensino aprendizagem.

De acordo com Pan (2008, p. 10), o desafio do trabalho pedagógico do professor regular, considera mais do que a adaptação do espaço físico, sendo viabilizadas metodologias 
apropriadas e a utilização de recursos didáticos que auxiliem o aluno na aprendizagem. Destaca Carneiro (2012), uma formação adequada deve garantir ao professor, a consciência do seu ensino, e a prática aplicada analisada no contexto no qual ocorre, e que a avaliação ocorra em todas as situações, e sempre tendo diversas soluções para que o problema seja resolvido.

De acordo com o segundo inciso da lei 12.764/12 que trata da Política Nacional de Proteção dos Direitos da Pessoa com Transtorno do Espectro Autista, destaca-se a capacitação de professores que na grande maioria vê-se incapazes de lidar com a educação inclusiva, diante dos alunos TEA, por possuir características marcantes, como as dificuldades na imaginação e na comunicação, no qual consta em todos os autista em que tem o direito de frequentar a escolar regular e a obrigação da escola de fornecer todos os recursos e adaptações para que a inclusão de fato aconteça.

De acordo com (BRASIL, 2012, p. 1), o autismo é caracterizado como:

I - deficiência persistente e clinicamente significativa da comunicação e das interações sociais, manifestada por deficiência marcada de comunicação verbal e não verbal usada para interação social; ausência de reciprocidade social; falência em desenvolver e manter relações apropriadas ao seu nível de desenvolvimento;

II - padrões restritivos e repetitivos de comportamentos, interesses e atividades, manifestados por comportamentos motores ou verbais estereotipados ou por comportamentos sensoriais incomuns; excessiva aderência a rotinas e padrões de comportamento ritualizados; interesses restritos e fixos.

Conforme Mantoan (2003) destaca que a educação inclusiva surge de politicas do sistema educacional de cada ambiente escolar, no qual pode gerar a ressignificação da identidade do aluno através dos professores e da comunidade escolar. Nesse sentido considera que a inclusão passa por momentos complexos, cada vez mais necessários, importante para constituir em uma formação humana e justa, abolindo o preconceito.

Para Carvalho (2008), a realidade de existir pessoas deficientes, a escola deve manter um posicionamento responsável para com todas as crianças sem discriminações.

\section{Método}

Esse estudo seguiu uma abordagem qualitativa durante a pesquisa e teve como procedimento metodológico o Estudo de Caso, utilizando como instrumento uma entrevista semiestruturada analisando as dificuldades enfrentadas de cada professora entrevistada durante a inserção do aluno TEA na sala de aula. 
De acordo com Ludke e André (1986, p. 17), relata que o Estudo de Caso surge a partir do interesse do pesquisador em determinado local no qual existe o problema a ser esclarecido no decorrer do estudo. "[...] o interesse incide naquilo que ele tem de único, de particular, mesmo que posteriormente venham a ficarem evidentes certas semelhanças com outros casos ou situações".

Sendo assim, os questionários foram respondidos pelas professoras, em que a professora do $1^{\circ}$ ano, chamada de $\mathrm{P} 1,2^{\circ}$ ano de $\mathrm{P} 2,3^{\circ}$ ano de $\mathrm{P} 3$ e o aluno autista $\mathrm{A}$, no presente artigo.

\section{Análise de dados}

A entrevista semiestruturada a ser analisada foi aplicada a três professoras do Ensino Fundamental I, com formação inicial em Pedagogia, numa escola do município de Bauru, em que cada professora teve e ou tem a experiencia de ter o mesmo aluno com TEA, respectivamente, no $3^{\circ}$ ano em 2018, no qual foram respondidos para posteriormente analisados.

Nessa perspectiva foram realizadas sete categorias para analisar as respostas das professoras, com o intuito de atender aos objetivos propostos. As categorias foram: Se as professoras sabiam o que é o autismo; O desenvolvimento da criança no trabalho pedagógico da escola; A família no processo da aprendizagem; Como é o trabalho do AEE; As dificuldades no trabalho pedagógico com o aluno TEA; A inclusão escolar de alunos autistas na visão das professoras; As dificuldades enfrentadas no desenvolvimento do aluno TEA pelas professoras.

O quadro 1 apresenta as informações acerca de cada carreira profissional docente entrevistada.

Quadro 1. Identificação e a formação docente da pesquisa.

\begin{tabular}{|c|c|c|c|c|}
\hline Identificação & $\begin{array}{r}\text { Fo } \\
\text { rmação } \\
\text { acadêmica }\end{array}$ & $\begin{array}{c}\text { Quantos } \\
\text { anos atuam como } \\
\text { docente }\end{array}$ & $\begin{array}{r}\text { Poss } \\
\text { ui pós- } \\
\text { graduação }\end{array}$ & Especifique \\
\hline P1 & $\begin{array}{r}\text { Ped } \\
\text { agogia }\end{array}$ & 9 anos & Sim & $\begin{array}{l}\text { Psicopedagogia; } \\
\text { Alfabetização } \\
\text { Letramento. }\end{array}$ \\
\hline $\mathbf{P 2}$ & $\begin{array}{l}\text { Ped } \\
\text { agogia }\end{array}$ & 9 anos & Sim & $\begin{array}{c}\text { Psicopedagogia } \\
\text { clínica e institucional; }\end{array}$ \\
\hline
\end{tabular}




\begin{tabular}{|r|r|r|l|}
\hline & & & $\begin{array}{l}\text { Educação Infantil; } \\
\text { Educação Sociedade e } \\
\text { Inclusão social; } \\
\text { Educação, Sociedade e } \\
\text { Inclusão Social com } \\
\text { ênfase em autismo. }\end{array}$ \\
\hline P3 & agogia & Ped & Sim \\
& & & $\begin{array}{l}\text { Psicopedagogia; } \\
\text { Neuroeducação; } \\
\text { Neuroaprendizagem; } \\
\text { Neurociência } \\
\text { Graduação } \\
\text { Psicologia. }\end{array}$ \\
\hline
\end{tabular}

Fonte: Elaboração própria ou dos autores

\section{Autismo}

A primeira questão realizada na entrevista foi sobre o conhecimento das professoras a respeito do conceito sobre o autismo. Com base nas respostas, pode destacar:

"É um transtorno do desenvolvimento que compromete as habilidades de comunicação e interação social da criança." (P1).

"É um transtorno de desenvolvimento grave incurável, que prejudica a capacidade de se comunicar e de interagir." (P2).

"É um transtorno de desenvolvimento que dificulta ou impede as habilidades sociais, a interação, a comunicação. Pode também ser associado a outras comorbidades: intelectuais, dislexias, dispraxias, TDAH." (P3).

Assim a partir das respostas das professoras sobre o autismo, é possível perceber que há uma concepção básica sobre o assunto.

Diante das respostas fornecidas, de acordo com Cunha (2012, p.24) o autismo pode aparecer nos primeiros meses de vida sendo perceptível em torno dos três anos de idade no qual é feita a avaliação diagnostica com a ajuda de psiquiatra ou neurologista e com o auxílio de outras especialidades, sendo que, uma das formas de manifestação apresentada acontece quando há um desejo por algo ou lugar, a criança utiliza o dedo para apontar, destacando as dificuldades para responder comandos de voz em que os sinais visuais são utilizados, nesse aspecto resultando na anulação da interação social da criança. 


\title{
O desenvolvimento da criança autista no trabalho pedagógico da escola
}

Como segunda categoria de análise da entrevista destaca-se, a maneira de como ocorre o trabalho pedagógico da escola tendo como objetivo o desenvolvimento do educando.

\begin{abstract}
"Necessitava de cuidadora presente de forma efetiva em sala de aula para que aceitasse as orientações da professora. As atividades eram adaptadas e o aluno as desenvolvia com auxílio. A sala de aula não podia ter muitos cartazes coloridos ou muitas informações, ou seja, poluição visual." (Pl).

"A criança autista está inserida no contexto integral da escola, mas por ter suas particularidades como gosto cognitivo nível intelectual, etc, é importante que a equipe pedagógica identifique as principais características positivas e negativas com a finalidade de trabalhar tais pontos, isso é feito com a ajuda pedagógica do histórico (laudo) da criança $e$ o comprometimento da equipe escolar junto as instituições que atendem a criança. " (P2).

"Tentamos desenvolver uma rotina que possa gerar segurança para trabalhar diversas habilidades. O aluno objeto desse processo esta em fase de alfabetização e realiza atividades próprias desse ciclo." (P3).
\end{abstract}

Através das respostas fornecidas pelas professoras, verifica que há conhecimento da importância do trabalho pedagógico realizado no ambiente escolar para com o A.

Nesse aspecto é de extrema importância trabalhar a socialização das crianças com autismo, dentro do ambiente escolar, em que deve estabelecer relações com outros alunos. De acordo com Silva (2012, p. 107), a vida escolar é um direito de todos em que favorece a socialização e a formação de um adulto consciente, aprendendo e respeitando as diferenças.

Diante disso, Silva e Almeida (2012), enfatizam que várias práticas exercidas com o educando exigem organização e atenção na elaboração das atividades de maneira lúdica, a fim de atingir o objetivo planejado, desenvolvendo a autonomia, a cooperação dos colegas, propiciar a participação de todos durante ensino-aprendizagem, tendo como resultado o avanço do educando em relação aos conhecimentos e independência.

Seguindo nessa linha, a equipe pedagógica escolar deve se atentar-se as necessidades educacionais antecipadamente, criando estratégias para avaliar o ensino executado pelo aluno A, diante dos objetivos pressupostos, no qual o planejamento deve ser participativo, a fim de tornar mais inclusivo o processo.

\section{A família no desenvolvimento da aprendizagem}

A terceira categoria, destaca o envolvimento da família durante a aprendizagem da criança, tendo a participação nas reuniões de pais e ou responsáveis, ocorridas bimestralmente na unidade escolar, quanto ao auxilio nas tarefas propostas pela professora regular, a 
preocupação em que de maneira propiciar a melhor metodologia para a compreensão dos conteúdos. Nesse aspecto, considera as respostas fornecidas pelas professoras:

"A família do aluno A não era presente na vida escolar dele. Não auxiliava com as tarefas enviadas para casa e nem garantia sua frequência às aulas. Durante o ano letivo ele saiu da escola duas vezes, sendo transferido para outra cidade e retornando um ou dois meses depois." (P1).

"A família muitas vezes é crítica no processo junto com a entidade que atende não percebo interesse no desenvolvimento da criança no processo." (P2).

“Não existe participação efetiva." (P3).

De acordo com Lopes e Marquezan (2000), das respostas analisadas, a importância da família é imprescindível nas influencias sociais e escolar sobre a criança, havendo nesse contexto a conscientização dos professores em que maneira trabalhar o desenvolvimento familiar do aluno, resultando na participação ativa no processo da aprendizagem.

Assim sendo, Dessen e Polonia (2007, p. 01), afirmam que "Escola e família constituem dois contextos de desenvolvimento fundamentais para a trajetória de vida das pessoas", tornando-os cidadãos ativos.

A participação da família com a inclusão do aluno A, não foi favorável levando em consideração ao aprendizado e o comportamento, no qual não o auxiliava nas tarefas, não havia participação nas reuniões do bimestre e nem com a escola e pela professora especialista quando requisitada.

\section{Atendimento Educacional Especializado (AEE)}

A quarta categoria, destaca a importância do AEE na escola, em que a professora da sala de recursos, especialista da Educação Especial, auxilia a professora regular, no qual se trabalha com materias adaptados conforme as especificidades do educando e em que a frequência do atendimento ocorre, de acordo com o comprometimento (física, intelectual ...).

Considera as respostas sobre o AEE na escola:

"Recebem atendimento da professora especialista duas vezes na semana, com duração de 50 minutos cada atendimento. Os materiais utilizados são adaptados de acordo com a necessidade." (P1).

"A escola oferece um AEE, através da sala de recursos, em que a criança tem atendimento em seu contraturno escolar por um professor especializado afim de desenvolver suas habilidades e minimizar os reflexos de seu comprometimento que podem prejudicar a interação social, aprendizagem, concentração, comunicação, etc." (P2).

"Ocorre em ambiente próprio com professora especializada." (P3). 
Para Brasil (2013, p. 303), a resolução n. ${ }^{\circ}$ 4/2009, Art. $9^{\circ}$ indica, que em se tratando do AEE, os professores especialistas são responsáveis pela articulação com a professora regular e entre outros profissionais da saúde que fazem o acompanhamento fora do ambiente escolar.

Nesse aspecto o AEE, deve estimular o educando através de diversos materiais educativos inclusivos junto com a professora conforme o conteúdo dado para os demais da sala, acompanhar com as entidades a frequência nos atendimentos fora da escola como a utilização de fisioterapia, psicóloga e terapeuta ocupacional entre outros, profissionais estes empenhados em proporcionar uma vivencia o mais integral possível, criando metodologias com o intuito de facilitar a aprendizagem.

\section{As dificuldades enfrentadas no trabalho pedagógico com o aluno TEA}

A quinta categoria relata, através das respostas dadas, as experiencias vivenciadas e ou vivencia com o educando, destacando o trabalho pedagógico.

Dessa forma as professoras responderam da seguinte maneira:
"No caso do A, era bem complicado, pois não me aceitava como orientadora. Não respondia a comandos nem realizava as atividades, bem como alterava seu comportamento sem a presença da cuidadora. Gritava, batia, saia correndo, desafiava...
"Como saiu da escola duas vezes e retornou somente um ou dois meses depois em cada mudança, foi bem complicado realizar um trabalho eficiente com o A. Não havia sequencia do trabalho e nem rotina adequada, pois se ausentava demais." (P1).
"Acho de suma importância a professor se preparar para lidar com os alunos autistas, sendo que o mesmo é um dos principais responsáveis pela construção do conhecimento pedagógico no aluno, os valores, e as normas sociais." (P2).
"Usando estratégias diversas, mas neste caso especifico, utilizo trocas e o auxílio de cuidadoras." (P3).

Através dos relatos, percebe que o trabalho docente/pedagógico deve ser bem trabalhado para educando com TEA, sendo um desafio pelas professoras em manter um efetivo trabalho, assim o "acesso para crianças e adolescentes com necessidades educacionais especiais, mas, sobretudo, garantir condições indispensáveis para que possam manter-se na escola e aprender." (SILVEIRA et al 2008).

Percebe no contexto, que possui um abismo no ensino aos educandos, com o fato de existir dúvidas e inseguranças nas práticas aplicadas. De acordo com Ferrari (2007), através das dificuldades vencidas, surge uma conscientização e diálogo, havendo trocas entre os colegas, a fim de encontrar a melhor maneira de incluir o educando. 
Nesse segmento, considera importante a formação dos professores, na preparação de atividades pedagógicas adaptadas em que o educando seja capaz de realizar com autonomia e ou auxilio de cuidadoras disponíveis na unidade escolar.

\title{
A inclusão escolar de alunos autistas na visão das professoras
}

A sexta categoria destaca a visão da inclusão dos alunos autistas, de acordo com cada professora, respectivamente:

\begin{abstract}
"A equipe escolar se esforça, mas faltam profissionais para auxiliar como: cuidadores, professores especialistas em TEA.

"As salas são superlotadas e o trabalho fica comprometido. " (P1).

"A inclusão escolar tem como objetivo inserir sem distinção todos as crianças com diversos graus de comprometimento social e cognitivo em ambiente escolar tradicional, com intuito de diminuir o preconceito $e$ estimular a socialização das pessoas com o desenvolvimento atípico para que desfrutem dos espaços e ambientes comunitários, contudo o professor se depara com a demanda de alunos e tem a obrigação de educa-los em um ambiente onde já está estabelecida uma metodologia de ensino especifica criada para um padrão de aluno e em meu ponto de vista, esse professor não está apto para suprir as necessidades expressas pelo aluno com autismo e suas dificuldades." (P2).

"Enfrentamos muitas dificuldades, pois não existe uma estrutura própria para isso: salas superlotadas (tenho 31 alunos sendo que 3 possuem laudos), formação adequada, materiais didáticos apropriados, organização didática, consenso entre os vários profissionais que o atendem." (P3).
\end{abstract}

De acordo com as respostas da entrevista, a inclusão escolar engloba todas as crianças independentes de serem deficientes ou não, religião, costumes etc, portanto a inclusão deve ser ofertada para todos a fim de oferecer a aprendizagem. Para Mantoan (2015, p. 28) assegura que a inclusão “[...] prevê a inserção escolar de forma radical, completa e sistemática. Todos os alunos, sem exceção, devem frequentar as salas de aula do ensino regular".

A educação inclusiva tornou uma tarefa sendo trabalhada a muitos anos. Nesse sentido Sapon-Shevin (1999, p. 288) onde os alunos sejam acolhidos e respeitados sendo aplicado diversas metodologias dos conteúdos diante do currículo.

Seguindo essa linha, ao pensar nas crianças com deficiência, a preocupação da comunidade escolar deve ser mais pontual ao propor atividades adaptadas conforme o conteúdo dado aos outros alunos considera nessa percepção, que a escola necessita ofertar condições para o atendimento aos alunos com necessidades educacionais especiais, refletir na transformação de modo em que todos participem do processo de aprendizagem. 


\section{As dificuldades enfrentadas no desenvolvimento do aluno TEA pelas professoras}

A sétima e última categoria, corresponde a relatos perante as dificuldades enfrentadas pelas professoras no desenvolvimento do educando autista. De acordo com P1, P2 e P3.

\footnotetext{
"É preciso ter uma rotina muito bem estabelecida e profissionais capacitados que possam auxiliar a professora da sala de aula comum." (P1).

"A falta de comunicação da criança (muitas vezes não verbalizam), a dificuldade na interação social, a falta de capacidade de se colocar no lugar do outro, a dependência para autocuidado e dificuldades cognitivas são umas das várias complicações no desenvolvimento da criança autista.

Além do impacto ao receber um aluno autista, acredito que a maior dificuldade é o despreparo, impedindo de identificar corretamente as necessidades desse aluno no primeiro momento. Isso gera ideias distorcidas sobre as possibilidades de educação desses alunos e a de lidar com seus problemas de comportamento. Nesse sentido o professor vê seu aluno sob o ângulo de suas limitações, e com isso gera um comprometimento da prática pedagógica a ser desenvolvida." (P2).

"Embora seja uma lei, muitas escolas não estão preparadas para receber crianças autistas. Há falta de criação de estratégias de aprendizagem, recursos, orientação profissional adequado a especificidade da criança atendida, para que se possa promover interações significativas.

A inclusão é muito importante, mas é necessário se pensar soluções para adequar a escola para receber esse aluno e não o aluno se adequar a escola, como vem acontecendo." (P3).
}

De acordo com a P1, a falta de comunicação do educando autista, deve ser destacada, porque não existe o feedback imediato, por essa razão é necessário que tenha alguém para o cuidar fisicamente do mesmo e estratégias para distinguir o desejo expressado, como a utilização de rotinas e fichas, com o auxílio da professora especialista diante da sua utilização.

Diante da resposta da $\mathrm{P} 2$, ao iniciar o período letivo e de repente saber que irá ter um aluno autista inserido na sua sala e não saber trabalhar com a inclusão, no qual gera um grande comprometimento de todos.

A P3, responde que apesar de ser lei, a escola não possui alicerces para se apoiarem, de acordo com a Política Nacional de Educação Especial na Perspectiva da Educação Inclusiva, as escolas regulares devem promover condições às necessidades educacionais dos alunos autistas, nesse ponto é relevante considerar que as escolas devem garantir recursos, formação continuada, continuamente eficaz de professores e a participação das famílias durante o processo de aprendizagem.

\section{Conclusões}


A proposta desse estudo de caso em torno do aluno (A) e das experiencias de três professoras (P1, P2 e P3), foi apresentar a maneira que o trabalho pedagógico é desenvolvido numa escola municipal de Bauru de Ensino Fundamental I, mediante os relatos fornecidas no questionário.

Assim de acordo com as políticas públicas inclusivas educacionais,

[...] devem ser concretizadas na forma de programas de capacitação e acompanhamento contínuo, que orientem o trabalho docente na perspectiva da diminuição gradativa da exclusão escolar, o que virá a beneficiar, não apenas os alunos com necessidades especiais, mas, de uma forma geral, a educação escolar como um todo. (GLAT; NOGUEIRA, 2003, p. 140).

O estudo demonstrou que as professoras sabem da importância de incluir qualquer aluno na escola sendo deficiente ou não, e relatam que apesar de existir políticas públicas educacionais no que diz a respeito da inclusão, a escola e as professoras não estão preparadas em oferecer uma aprendizagem integral que favoreça o aluno apesar de possuírem formação continuada sobre o assunto, ainda há um despreparo e informação em desenvolver um trabalho pedagógico efetivo.

Os resultados apresentaram que se faz necessário uma maior colaboração entre os profissionais da escola, e maior participação da família do aluno, para que a educação inclusiva seja verdadeiramente realizada.

Nesse contexto conclui através das respostas, que ainda possui uma precarização de orientação e conhecimento sobre a inclusão dos educandos com autismo sendo necessário atualização profissional constantemente realizada através de cursos de formação docente possibilitando condições de desempenharem de forma expressiva no ensino-aprendizagem, influenciando a sociedade como um todo perante a inclusão.

\section{REFERÊNCIAS}

BRASIL. Lei de Diretrizes e Bases da Educação Nacional. Lei n ${ }^{\circ}$ 9.394. Promulgada em 20 de dezembro de 1996. Brasília: Editora do Brasil, 1996.

BRASIL. Decreto $\mathrm{n}^{0}$ 6.571 de 17 de setembro de 2008. Dispõe sobre o atendimento educacional especializado. Presidência da República/Casa Civil/Subchefia para Assuntos Jurídicos. Brasília. 2008.

BRASIL. Resolução no 4, de 2 de outubro de 2009. Institui Diretrizes Operacionais para o Atendimento Educacional Especializado na Educação Básica, modalidade Educação Especial. Ministério da Educação/Conselho Nacional de Educação/ Câmara de Educação Básica. 2009. 
BRASIL. Lei $\mathbf{n}^{\mathbf{0}}$. 12.764, de 27 de dezembro de 2012. Institui a política nacional de proteção dos direitos da pessoa com transtorno do espectro autista; e altera o $\S 3^{\circ}$. do art. 98 da Lei ${ }^{\circ}$. 8.112, de 11 de dezembro de 1990. Disponível em: http://www.planalto.gov.br/ ccivil_03/ _ato2011-2014/2012/lei/112764.htm. Acesso em: 13 out. 2018.

BRASIL. Ministério da Educação. Conselho Nacional de Educação. Diretrizes Curriculares Nacionais da Educação Básica. Brasília: MEC, SEB, DICEI, 2013.

CARNEIRO, R. U. C. 2012. Formação de professores da Educação especial à inclusiva alguns apontamentos. IN: ZANIOLO, L. O.; DALL' ACQUA, M. J. C. Inclusão Escolar: pesquisando políticas públicas, formação de professores e práticas pedagógicas. Jundiaí: Paco Editorial, 2012.

CARVALHO, R. E. Escola Inclusiva: a reorganização do trabalho pedagógico. Mediação: Porto Alegre/RS. 2008.

CUNHA, E. Autismo e inclusão: psicopedagogia e práticas educativas na escola e na família. 4 ed. Rio de Janeiro: Wak, 2012.

FARIAS, I. R.; SANTOS, A. F.; SILVA, E. B. da. Reflexões sobre a inclusão linguística no contexto escolas. In: DÍAZ, F., et al, orgs. Educação inclusiva, deficiência e contexto social: questões contemporâneas [online]. Salvador: EDUFBA, 2009, pp. 39-48. Disponível em: http://books.scielo.org/id/rp6gk/pdf/diaz-9788523209285-04.pdf. Acesso em: 17 ago. 2018.

FÁVERO, O.; FERREIRA, T. I.; BARREIROS, D. Tornar a educação inclusiva. Brasília: UNESCO, 2009.

Ferrari, P. (2007). Autismo infantil: o que é e como tratar. (Tradução Marcelo Dias Almada). São Paulo: Paulinas (Coleção caminhos da psicologia).

GLAT, R.; NOGUEIRA, M. L. L.. Políticas educacionais e a formação de professores para a educação inclusiva no Brasil. Comunicações. São Paulo, v. 10. n. 1, p. 134-141, jun. 2003. Disponível em: https://www.metodista.br/revistas/revistas-

unimep/index.php/comunicacoes/article/view/1647. Acesso em: 27 set. 2016.

LOPES, R. P. V.; MARQUEZAN, R. O Envolvimento da Família no Processo de Integração/Inclusão do Aluno com Necessidades Especiais. Cadernos de Educação Especial, Santa Maria - RS, 2000.

LUDKE, M.; ANDRÉ, M. E.D. A. Pesquisa em educação: abordagens qualitativas. São Paulo: EPU, 1986.

MANTOAN, M. T. E. Inclusão escolar: o que é, por que é? Como fazer? São Paulo: Moderna, 2003.

PAN, M. A. G. S. A deficiência Intelectual e a Educação Contemporânea. In: FACION, José Raimundo (org.). Inclusão escolar e suas implicações. Curitiba: Ibpex, 2008. 
POLONIA, A.C.; DESSEN, M. A. Em busca de uma compreensão das relações entre família e escola. Psicologia Escolar e Educacional [online] Campinas, v. 9, n. 2, 2005. Disponível em: http://www.scielo.br/pdf/pee/v9n2/v9n2a12.pdf. Acesso em: 29 out. 2018.

RODRIGUES, D.; RODRIGUES, L.L. Formação de professores e inclusão: como se reformam os reformadores? [online] Educar em Revista, Curitiba, Brasil, n. 41, p. 41-60, jul./set. 2011. Editora UFPR. Disponível em: http://www.scielo.br/pdf/er/n41/04.pdf._Acesso em: 29 out. 2018.

SAPON-SHEVIN, M. Celebrando a diversidade, baseando-se nelas. In: STAINBACK, Susan; STAINACK, William. Inclusão: um guia para educadores. Porto Alegre: Artmed, 1999. p. 288-305.

SILVA, A. B. B. Mundo singular: entenda o autismo. Rio de Janeiro: Objetiva, 2012.

SILVA, S. F.; ALMEIDA, A. L. Atendimento Educacional Especializado para Aluno com Autismo: Desafios e possibilidades. INTL. J. of Knowl. Eng., Florianópolis, v. 1, no 1, p. 62$88,2012$.

SILVEIRA, A. P. Alunos com déficit intelectual: O processo de inclusão nas séries iniciais do ensino fundamental. Maringá. 2008.

\section{Como referenciar este artigo}

ONOHARA, A. M. H.; SANTOS CRUZ, José Anderson.; MARIANO, Maria Luiza. Educação inclusiva: o trabalho pedagógico do professor para com o aluno autista no ensino fundamental I. Doxa: Rev. Bras. Psico. e Educ., Araraquara, v. 20, n. 2, p. 289-304, jul./dez., 2018. e-ISSN: 2594-8385. DOI: 10.30715/doxa.v20i2.12020

Submetido em: 01/06/2018

Aprovado em: 25/10/2018 